\title{
PENGENALAN MANAJEMEN SAINS
}

\author{
Apriyan Aryatama \\ 185100015P \\ Fakultas Komputer \\ apriyanaryatama.student@,umitra.ac.id
}

\begin{abstract}
ABSTRAK
Seni dalam menyelesaikan pekerjaan melalui orang lain. Artinya bahwa para manajer dalam mencapai tujuan dengan menggunakan orang lain dan dalam penerapannya memerlukan seni sehingga pada setiap orang pasti berbeda meskipun menangani hal yang sama, karena seni setiap orang berbeda.

Manajemen adalah proses perencanaan, pengorganisasian pengarahan dan pengawasan usaha-usaha para anggota organisasi dan penggunaan sumberdaya organisasi lainnya agar dapat dapat digunakan mencapai tujuan organisasi yang telah ditetapkan
\end{abstract}

Kata Kunci : Pengenalan Manajemen Sains, Manajemen, Sains 


\section{A. PENDAhuluan}

Seni dalam menyelesaikan pekerjaan melalui orang lain. Artinya bahwa para manajer dalam mencapai tujuan dengan menggunakan orang lain dan dalam penerapannya memerlukan seni sehingga pada setiap orang pasti berbeda meskipun menangani hal yang sama, karena seni setiap orang berbeda.

Manajemen adalah proses perencanaan, pengorganisasian pengarahan dan pengawasan usaha-usaha para anggota organisasi dan penggunaan sumberdaya organisasi lainnya agar dapat dapat digunakan mencapai tujuan organisasi yang telah ditetapkan

Manajemen Diperlukan untuk :

1. Mencapai tujuan

2. Menjaga keseimbangan di antara tujuan-tujuan yang saling bertentangan

3. Mencapai efektifitas dan efisiensi

Manajemen Sains pada penggunaan metode ilmiah untuk menentukan cara terbaik dalam menyelesaikan suatu pekerjaan.

Manajemen Sains yaitu suatu ilmu yang menggunakan aplikasi matematika dalam menyelesaikan masalah yang dihadapi seorang manajer yang dijelaskan sebagai filosofi dan logika untuk memecakan masalah.
Manajemen Sains Tujuannya adalah :

menyelesaikan masalah-masalah yang dihadapi oleh manajer dalam proses pengambilan keputusan dengan pendekatan model-model matematika

Contoh Penerapan :

a. Realokasi Sumber Daya

b. Produksi Campuran

c. Penjadwalan

d. Keputusan Investasi

e. Perencanaan Produksi

f. Masalah transportasi, logistik

g. Dll

Pendekatannya :

1. Observasi

Mempelajari Masalah :

Suatu kondisi yang harus diantisipasi dan direncanakan

2. Definisi Masalah Penjabaran masalah dengan singkat

- Batasan -batasan masalah

- Tingkatan masalah tersebut mempengaruhi unit yang lain Ada masalah maka tujuan Perusahaan tidak tercapai.

3. Perumusan Model Penyajian ringkasan situasi masalah yang ada

- Menentukan variabel

- Hubungan sistematis

- Grafik

- Diagram 
4. Pemecahan Model

- Menentukan apakah model matematisnya sudah meng gambarkan keadaan nyata secara akurat

- Jika belum maka membuat model baru

5. Implementasi

Menterjemahkan hasil perhitungan ke dalam bahasa sehari-hari yang mudah dimengerti.

\section{B. HASIL DAN PEMBAHASAN}

PT X memproduksi dua jenis mainan dari kayu, yang berupa Boneka dan Kereta Api.

Boneka dijual dengan harga $\mathrm{Rp}$ 27.000 ,- yang biaya bahannya memerlukan biaya $\mathrm{Rp} 10.000$,serta biaya tenaga $\mathrm{Rp} 14.000,-$.

Sedang Kereta Api dijual dengan harga Rp 21.000,- dengan biaya bahan sebesar Rp 9.000,- dan tenaga $\mathrm{Rp} \quad 10.000,-$. Untuk mengerjakan diperlukan dua bagian tenaga kerja yaitu tukang kayu dan tukang poles.

\section{ID SECURITY \\ QWTD4452377-ASP-5244107}

\section{KESIMPULAN DAN SARAN}

Untuk mengerjakan boneka memerlukan waktu 1 jam pekerjaan tukang kayu dan 2 jam tukang poles sedang untuk kereta api diperlukan 1 jam pekerjaan tukang kayu dan 1 jam tukang poles Jam kerja yang tersedia untuk setiap minggunya 80 jam tukang kayu dan 100 jam tukang poles. Kebutuhan pasar untuk kereta api tidak terbatas sedang untuk boneka tidak lebih dari 40 . bagaimana formulasi dari masalah ini agar ke untungan maksimum?

\section{E. REFERENCE}

[1] O. M. Febriani and A. S. Putra, "Sistem Informasi Monitoring Inventori Barang Pada Balai Riset Standardisasi Industri Bandar Lampung," J. Inform., vol. 13, no. 1, pp. 90-98, 2014.

[2] A. S. Putra, "Paperplain: Execution Fundamental Create Application With Borland Delphi 7.0 University Of Mitra Indonesia," 2018.

[3] A. S. Putra, "2018 Artikel Struktur Data, Audit Dan Jaringan Komputer," 2018.

[4] A. S. Putra, "ALIAS MANAGER USED IN DATABASE DESKTOP STUDI CASE DB DEMOS."

[5] A. S. Putra, "COMPREHENSIVE SET OF PROFESSIONAL FOR DISTRIBUTE COMPUTING."

[6] A. S. Putra, "DATA ORIENTED RECOGNITION IN BORLAND DELPHI 7.0."

[7] A. S. Putra, "EMBARCADERO DELPHI XE 2 IN GPUPOWERED FIREMONKEY APPLICATION."

[8] A. S. Putra, "HAK ATAS KEKAYAAN INTELEKTUAL 
Tugas 1 - Manajemen Sains

DALAM

DUNIA

TEKNOLOGY BERBASIS

REVOLUSI INDUSTRI 4.0."

[9] A. S. Putra, "IMPLEMENTASI

PERATURAN

PERUNDANGAN UU. NO 31

TAHUN 2000 TENTANG

DESAIN INDUSTRI

BERBASIS INFORMATION TECHNOLOGY."

[10] A

S. Putra,

"IMPLEMENTATION OF

PARADOX DBASE."

[11] A.

A. S. Putra,

"IMPLEMENTATION OF

TRADE SECRET CASE

STUDY SAMSUNG MOBILE PHONE."

[12] A

"IMPLEMENTATION

PATENT FOR APPLICATION

WEB BASED CASE STUDI

WWW. PUBLIKLAMPUNG. COM."

[13] A.

"IMPLEMENTATION

SYSTEM FIRST TO INVENT IN DIGITALLY INDUSTRY."

[14] A. S. Putra, "MANUAL REPORT \& INTEGRATED DEVELOPMENT

ENVIRONMENT BORLAND DELPHI 7.0."

[15] A. S. Putra, "PATENT AS RELEVAN SUPPORT RESEARCH."

[16] A. S. Putra, "PATENT FOR RESEARCH STUDY CASE OF APPLE. Inc."

[17] A. S. Putra, "PATENT PROTECTION FOR APPLICATION INVENT."

[18] A. S. Putra, "QUICK REPORT IN PROPERTY PROGRAMMING.'”
[19] A. S. Putra, "REVIEW CIRCUIT LAYOUT COMPONENT

REQUIREMENT ON ASUS NOTEBOOK."

[20] A. S. Putra, "REVIEW TRADEMARK PATENT FOR INDUSTRIAL TECHNOLOGY BASED 4.0."

[21] A. S. Putra, "TOOLBAR COMPONENT PALLETTE IN OBJECT ORIENTED PROGRAMMING."

[22] A. S. Putra, "WORKING DIRECTORY SET FOR PARADOX 7."

[23] A. S. Putra, "ZQUERY CONNECTION

IMPLEMENTED

PROGRAMMING STUDI CASE PT. BANK BCA Tbk."

[24] A. S. Putra, D. R. Aryanti, and I. Hartati, "Metode SAW (Simple Additive Weighting) sebagai Sistem Pendukung Keputusan Guru Berprestasi (Studi Kasus: SMK Global Surya)," in Prosiding Seminar Nasional Darmajaya, 2018, vol. 1, no. 1, pp. 85-97.

[25] A. S. Putra and O. M. Febriani, "Knowledge Management Online Application in PDAM Lampung Province," in Prosiding International conference on Information Technology and Business (ICITB), 2018, pp. 181-187.

[26] A. S. Putra, O. M. Febriani, and B. Bachry, "Implementasi Genetic Fuzzy System Untuk Mengidentifikasi Hasil Curian Kendaraan Bermotor Di Polda Lampung," SIMADA (Jurnal Sist. Inf. dan Manaj. Basis 
Data), vol. 1, no. 1, pp. 21-30, 2018.

[27] A. S. Putra, H. Sukri, and K. Zuhri, "Sistem Monitoring Realtime Jaringan Irigasi Desa (JIDES) Dengan Konsep Jaringan Sensor Nirkabel," IJEIS (Indonesian J. Electron. Instrum. Syst., vol. 8, no. 2, pp. 221-232.

[28] D. P. Sari, O. M. Febriani, and A. S. Putra, "Perancangan Sistem Informasi SDM Berprestasi pada SD Global Surya," in Prosiding Seminar Nasional Darmajaya, 2018, vol. 1, no. 1, pp. 289-294. 